\title{
Effects of an On-Board Safety Device on the Emissions and Fuel Consumption of a Light Duty Vehicle
}

\author{
Cheuk Yin Ng, Yuhan Huang, Guang Hong, John Zhou, and Nic Surawski \\ University of Technology Sydney
}

\author{
Jackson Ho \\ THEi

\section{Edward Chan} \\ VTC
}

\begin{abstract}
Vehicle emissions and fuel consumption are significantly affected by driving behavior. Many studies of eco-driving technology such as eco-driving training, driving simulators and on-board eco-driving devices have reported potential reductions in emissions and fuel consumption. Use of on-board safety devices is mainly for safety, but also affects vehicle emissions and fuel consumption. In this study, an on-board safety device was installed to alert the driver and provide several types of warning to the driver (e.g. headway monitoring warning, lane collision warning, speed limit warning, etc.) to improve driving behavior. A portable emissions measurement system (PEMS) was used to measure vehicle exhaust concentrations, including hydrocarbons $(\mathrm{HC})$, carbon monoxide $(\mathrm{CO})$, carbon dioxide $\left(\mathrm{CO}_{2}\right)$ and nitrogen oxides (NOx). The driving parameters including vehicle speed, acceleration and position were also recorded. A specific test route was designed for the experiment to investigate both urban and highway conditions. The driving parameters and emissions data were compared before and after the installation of the on-board safety device with the same driver. The Vehicle Specific Power (VSP) methodology was applied to evaluate the effects of the on-board safety device on driving behavior. The results indicated that the device had a positive effect on the driver's driving behavior. The percentage of time spent on excessive speeding and strong acceleration decreased from $22.2 \%$ to $14.7 \%$. As a result, an average reduction of $25 \%$ in fuel consumption was observed. In addition, $\mathrm{HC}$, $\mathrm{CO}_{2}$ and $\mathrm{NOx}$ emissions showed a reduction of $57 \%, 25 \%$ and $9 \%$ respectively. However, $\mathrm{CO}$ emission was increased and the time spent on idling showed no change with the installation of the device.
\end{abstract}

\section{Introduction}

Road transport is an important source of air pollutants and greenhouse gases. About $26 \%$ of total $\mathrm{CO}_{2}$ emissions was contributed by the transport sector in Europe [1]. An increasing amount of $\mathrm{CO}_{2}$ emissions and other greenhouse gases such as methane $\left(\mathrm{CH}_{4}\right)$ and nitrous oxide $\left(\mathrm{N}_{2} \mathrm{O}\right)$ has received considerable attention from policy makers and environmental groups. In order to reduce the negative impacts from the transport sector, policies and technologies for air pollution control are being introduced to control the vehicle emissions, to reduce the concentration of air pollutants and the reduction in emissions quantity [2, 3]. In Hong Kong, road transport emissions are a major source of air pollution. The Hong Kong SAR Government has implemented a series of policies and motor vehicle emission control programs to improve ambient and roadside air

Page 1 of 8 quality including progressively phasing out 82,000 pre-Euro IV diesel commercial vehicles by the end of 2019, retrofitting light and heavy duty vehicles with Diesel Particulate Filters (DPF) and Diesel Oxidation Catalysts (DOC) [4], subsidizing a 300 million HKD fund for the testing of green and innovative transport technologies, offering training sessions on proper engine repair and maintenance to reduce emissions from vehicles and organizing eco-driving seminars for the public and relevant trade associations etc.

Many studies of eco-driving technology have reported that driving behavior has a significant influence on fuel consumption and $\mathrm{CO}_{2}$ emissions. Eco-driving is a relatively simple and low-cost option for addressing the problem of climate change and air pollution control. It has been noted that eco-driving technology had potential in reducing the fuel consumption and $\mathrm{CO}_{2}$ emissions ranged from $5 \%$ to $40 \%$ [5]. Sivak and Schoettle [6] reported that the decisions made by a driver significantly affected the fuel economy of light-duty vehicles. The effect of drivers' decisions could be grouped into three categories, including strategic decisions (selection of vehicle and vehicle maintenance), tactical decisions (optimization of route choice and vehicle load) and operational decisions (driving behavior). It was found that aggressive driving behaviour resulted in high emissions and fuel consumption and that maintaining an eco-driving style could reduce fuel consumption by $5-30 \%$. Imaizumi and Sengoku [7] observed that smooth traffic conditions and the promotion of ecodriving also improved fuel consumption. In addition to fuel consumption, traffic flow smoothing is also effective for shortening travel period. Bensen et al. [8] analyzed eco-driving training courses and concluded that these courses could be short-lived as drivers tended to slip back into old habits.

An on-board feedback device has the potential to reduce $\mathrm{CO}_{2}$ emissions and enhance fuel economy by encouraging good driving behaviour. Orfila et al. [9] investigated on-board eco-driving applications. Their results showed that the on-board eco-driving device could provide real time feedback and information precisely and reliably to the driver by getting vehicle's information from the on-board diagnostic II (OBD II) connector. This feedback information could lead to significant reduction in fuel consumption and improvement in road safety. However, Dijksterhuis et al. [10] reported that the delayed feedback (given via a website) on driving behaviour was convenient in that it allows for complete transmission of a dataset to the driver in a flexible way.

The aim of this study was to investigate the impact of an on-board safety device on fuel consumption and emissions from a light duty 
vehicle. An on-board safety device was installed to provide real time feedback to the driver. It was originally used to alert the driver of a potentially dangerous situation and unindicated lane departure to improve driving behaviour. The emissions data were measured and recorded by a PEMS system. In addition, the driving parameters including vehicle speed, acceleration and position were also recorded. A specific test route was designed for the experiments to cover both urban and highway conditions. The emissions data and fuel economy before and after the installation of the on-board safety device were compared and analyzed by the VSP model.

\section{Experimental setup and analytical methods}

\section{Testing vehicle}

In Hong Kong, there were a total number of 112,027 registered goods vehicles in 2017, including light, medium and heavy goods vehicles. Around 70,000 light goods vehicles were registered and travelling on road $[11,12]$. Thus, a light goods diesel vehicle was selected to install a PEMS equipment and perform the road test in this study. The tested light goods vehicle (Figure 1) was equipped with emissions reduction devices including exhaust gas recirculation (EGR) and diesel oxidation catalyst (DOC). EGR recirculates a controllable proportion of the engine exhaust gas which is mixed with the intake air to reduce the $\mathrm{NO}_{\mathrm{x}}$. DOC is a modern catalytic converter consisting of a monolith honeycomb substrate coated with platinum group metal catalyst and packaged in a stainless steel container. It was used to oxidize $\mathrm{CO}$ and $\mathrm{HC}$ into $\mathrm{CO}_{2}$ and $\mathrm{H}_{2} \mathrm{O}$. The technical parameters of the light goods vehicles are shown in Table 1.

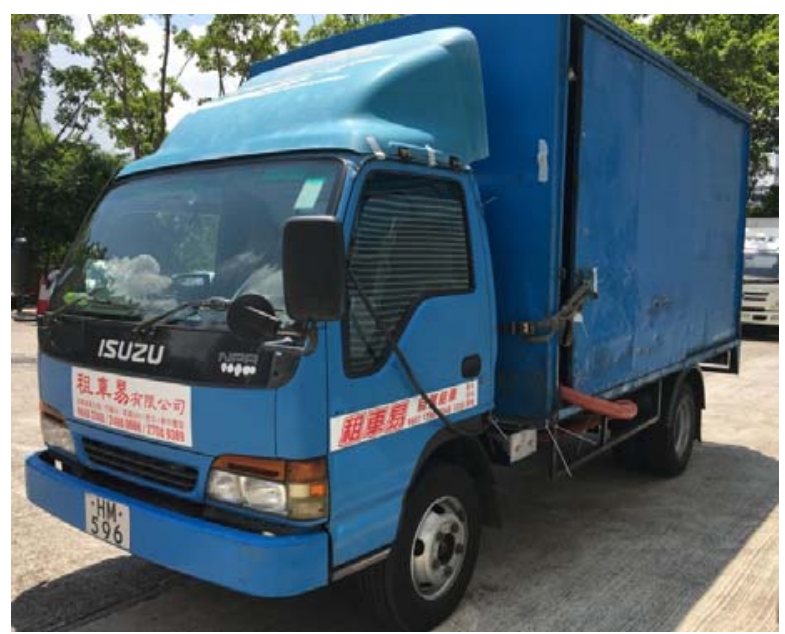

Figure 1. The 5.5 tons light goods vehicle used for on-road emission testing.

Table 1. The specifications of the test vehicle.

\begin{tabular}{|l|l|}
\hline Manufacturer & ISUZU \\
\hline Model & NPR70 \\
\hline Year & 2003 \\
\hline Engine size (c.c.) & 4751 \\
\hline Gearbox & Manual \\
\hline Gross vehicle weight (kg) & 5500 \\
\hline Odometer & 474451 \\
\hline
\end{tabular}

The on-road emission test experiments were conducted in two different stages with the same driver. A specific test route was Page 2 of 8 designed for the experiment, including urban and highway conditions. In order to collect urban and highway driving data, a test route (Figure 2) was constructed with around $2 \mathrm{~km}$ travelled along an urban path and $14 \mathrm{~km}$ on a highway with a total test duration of 18 minutes. The experimental test route is a typical and popular route in Hong Kong. In the first stage of the experiment, the driver was requested to drive along the route normally. In the second stage of experiment, an on-board safety device was installed on the test vehicle. The on-board safety device was used to alert the driver of a potentially dangerous situation and improve driving behavior. Both driving parameters and emissions data were collected during the experiments. The experiments were conducted at 11:30 a.m. to 12:30 p.m. and repeated at 3:30 p.m. to 4:30 p.m. on the same day, to avoid peak hours and maintain relatively low traffic density which allowed the driver to drive as his own driving style in stage 1 .

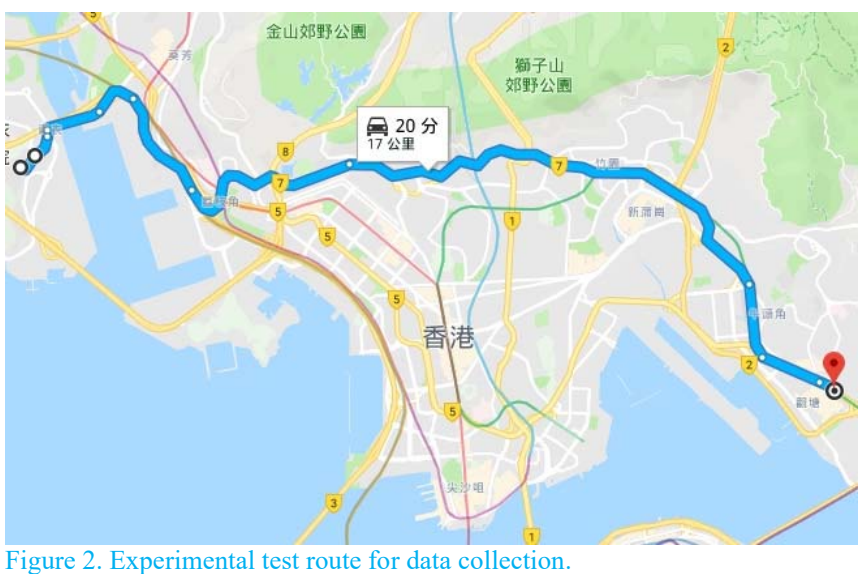

\section{Portable emissions measurement system}

A PEMS installed on the test vehicle was used to record real-world emissions data. PEMS is a mobile instrument that is used on-board to measure vehicle emissions under real driving conditions. PEMS integrates advanced gas analysers, an exhaust flow meter, a weather station and a Global Positioning System (GPS). As shown in Figure 3 , the emission gas sample line and exhaust flow measurement system are directly connected to the exhaust pipe. The exhaust emissions flow rate and temperature can be monitored in real-time together with ambient meteorological parameters.

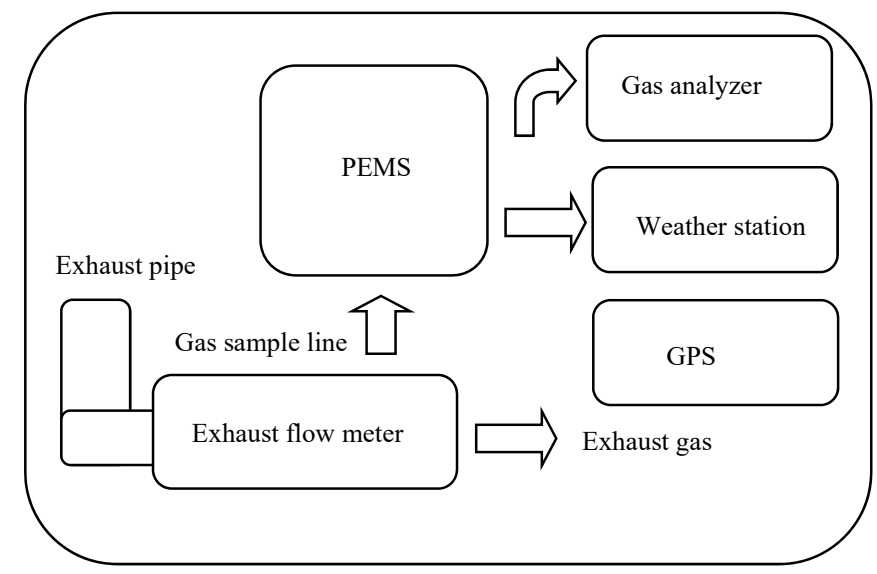

Figure 3. Block diagram of PEMS 
PEMS typically measures instantaneous raw exhaust gas from the tailpipe, including $\mathrm{HC}, \mathrm{CO}, \mathrm{CO}_{2}$ and $\mathrm{NO}_{x}$. An EMS 5003 emissions gas analyzer was integrated into the PEMS system. $\mathrm{HC}, \mathrm{CO}$ and $\mathrm{CO}_{2}$ are measured by Non-Dispersive Infra-Red detection (NDIR) and the NOx sensors are electrochemical cells. The technical parameters of the emissions gas analyzer are shown in Table 2.

Table 2. The specifications of the EMS 5003 emissions gas analyzer.

\begin{tabular}{|l|l|l|l|}
\hline Gas & Standard Range & Resolution & Accuracy \\
\hline $\mathrm{HC}$ & Propane: $0-4000 \mathrm{ppm}$ & $1 \mathrm{ppm}$ & $\pm 4 \mathrm{ppm}$ or 3\% reading \\
\hline $\mathrm{CO}$ & $0-15 \%$ & $0.01 \%$ & $\begin{array}{l} \pm 0.02 \% \mathrm{ppm} \text { or } 3 \% \\
\text { reading }\end{array}$ \\
\hline $\mathrm{CO}_{2}$ & $0-20 \%$ & $0.1 \%$ & $\begin{array}{l}0.3 \% \mathrm{ppm} \text { or } 3 \% \\
\text { reading }\end{array}$ \\
\hline $\mathrm{NOx}$ & $0-5000 \mathrm{ppm}$ & $1 \mathrm{ppm}$ & $\begin{array}{l}25 \mathrm{ppm} \text { or } 4 \% \text { reading } \\
\text { in } 0-4000 \mathrm{ppm} \\
25 \mathrm{ppm} \text { or } 8 \% \text { reading } \\
\text { in } 4001-5000 \mathrm{ppm}\end{array}$ \\
\hline
\end{tabular}

Table 3. Key parameters collected by the PEMS

\begin{tabular}{|l|l|l|}
\hline Index & Parameter & Unit \\
\hline 1 & Hydrocarbons & $\mathrm{ppm}$ \\
\hline 2 & Carbon monoxide & $\%$ \\
\hline 3 & Carbon dioxide & $\%$ \\
\hline 4 & Nitrogen oxides & $\mathrm{ppm}$ \\
\hline 5 & Ambient temperature & ${ }^{\circ} \mathrm{C}$ \\
\hline 6 & Ambient humidity & $\%$ \\
\hline 7 & Ambient pressure & $\mathrm{mbar}$ \\
\hline 8 & Exhaust flow rate & $\mathrm{kg} / \mathrm{hr}$ \\
\hline 9 & Exhaust flow temperature & ${ }^{\circ} \mathrm{C}$ \\
\hline 10 & Vehicle speed & $\mathrm{km} / \mathrm{h}$ \\
\hline 11 & Vehicle position & - \\
\hline
\end{tabular}

A weather station is mounted on the roof of the test vehicle to measure and record the ambient temperature, relative humidity and atmospheric pressure during on-road testing. In addition, a battery pack consisting of three lead acid batteries are mounted in the trunk to supply power for the instruments. At the same time, the vehicle position was detected by a GPS module, including time, vehicle speed and altitude. In the present study, all the data were recorded at a sample rate of $1 \mathrm{~Hz}$ and sent to the internal storage of a notebook computer. The key recorded parameters are shown in Table 3.

\section{On-board safety device}

An on-board safety device was installed on the test vehicle in the second stage of the experiment. As shown in Figure 4, the on-board safety device consisted of an in-car feedback system and a Mobileye ADAS sensor. They were developed to collect raw driver operation data under real traffic condition, including driver operation data and a driving video. All acquired data were recorded in the internal SD card and uploaded to a server. An in-car feedback system consisted of a driving user interface and provided several types of warning to the driver when abnormal driving was occurred. Those warnings include:
1. Headway Monitoring Warning,

2. Lane Departure Warning,

3. Forward Collision Warning,

4. Pedestrian Collision Warning,

5. Speed Limit Warning.

The in-car feedback system provided real-time warnings to alert the driver and improve driving behavior, including warnings on:

1. Excessive speeding [5],

2. Frequency and intensity of acceleration and braking,

3. Hard acceleration and braking [13],

4. Engine idling time [14].

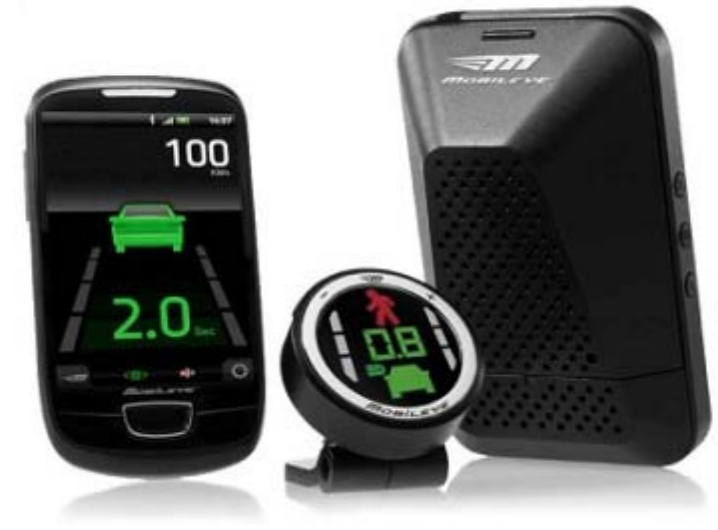

Figure 4. On-board safety device - Mobileye.

\section{Data analysis using VSP methodology}

Real-world emissions data and driving parameters were collected by the PEMS equipment. Various models have been developed recently to analyze a vehicle's environmental performance. In this study, the Vehicle Specific Power (VSP) methodology was adopted to fulfill the objectives of the present study by calculating the percentage of time spent in different driving patterns, including deceleration, idling, acceleration and hard acceleration. VSP is defined as the engine power output per unit mass of the vehicle. It is expressed as a function of vehicle speed, vehicle acceleration and road grade [15]. The advantage of the VSP methodology is that the vehicle's specific power can be directly calculated from the data acquired in the experiments. The emissions level can be quantified by the driving parameters of the vehicle. The VSP was calculated with Equation (1) which was developed for applications involving light-duty vehicles [16]:

$V S P=1.1 \cdot v \cdot a+9.81 \cdot \operatorname{grade} \cdot v+0.213 \cdot v+3.05 \cdot 10^{-4} \cdot v^{3}$

where VSP is vehicle specific power (W/kg), $v$ is the instantaneous vehicle velocity $(\mathrm{m} / \mathrm{s}), a$ is the instantaneous vehicle acceleration $\left(\mathrm{m}^{2} / \mathrm{s}\right)$, and grade is defined as vertical rise/horizontal distance.

Page 3 of 8 
In the experiments, the test vehicle was driven in a round trip to measure and record on-road emission data. The driver made a trip to a destination and returned over the same route. Thus, the road grade effect was ignored and not included in the calculations. Based on the recorded data, VSP values were calculated and grouped into discrete modes. The driving condition is defined based on the VSP mode [17]. As shown in Table 4, VSP is divided into 14 modes. The negative values of VSP in modes 1 and 2 are grouped into one, as they represent the test vehicle decelerating. Idling is represented in mode 3. Modes 4 to 7 represent the acceleration and steady speed conditions of the test vehicle. Beyond mode 7, the higher the acceleration and speed the vehicle reaches, the higher the mode. They also represent higher power demand to the engine.

Table 4. Vehicle specific power modal range [17]

\begin{tabular}{|c|c|c|}
\hline Vehicle specific power $(\mathrm{W} / \mathrm{kg})$ & VSP Mode & Driving condition \\
\hline$V S P<-2$ & 1 & \multirow{2}{*}{ Deceleration } \\
\hline$-2 \leq V S P<0$ & 2 & \\
\hline $0 \leq V S P<1$ & 3 & Idling \\
\hline $1 \leq V S P<4$ & 4 & \multirow{4}{*}{ Normal driving } \\
\hline $4 \leq V S P<7$ & 5 & \\
\hline $7 \leq V S P<10$ & 6 & \\
\hline $10 \leq V S P<13$ & 7 & \\
\hline $13 \leq V S P<16$ & 8 & \multirow{7}{*}{ Heavy acceleration } \\
\hline $16 \leq V S P<19$ & 9 & \\
\hline $19 \leq V S P<23$ & 10 & \\
\hline $23 \leq V S P<28$ & 11 & \\
\hline $28 \leq V S P<33$ & 12 & \\
\hline $33 \leq V S P<39$ & 13 & \\
\hline$V S P \geq 39$ & 14 & \\
\hline
\end{tabular}

\section{Results and discussion}

Results will be presented and discussed in two sections. The first investigates the safety performance and the comparison of the VSP time distributions in each mode in two stages of the experiments, and the second for the effect of the on-board safety device on emissions and fuel consumption.

As shown in Table 5, the experiments were conducted on two days, including four trips with $128 \mathrm{~km}$ being travelled which was evenly distributed over two stages of experiments both with and without the on board safety device. The impact of the ambient temperature on the recorded data was negligible because the variation of the ambient temperature was less than 2 degrees.

Table 5. Monitored driving data.

\begin{tabular}{|l|l|l|}
\hline & Stage 1 & Stage 2 \\
\hline Travelling time per trip (minutes) & 46 & 49 \\
\hline Travelling distance per trip (km) & 32 & 32 \\
\hline Number of Trips & 2 & 2 \\
\hline
\end{tabular}

\section{Safety performance and VSP time distributions}

As introduced previously, in the first stage of the experiments, the driver was requested to drive in their normal pattern and style without the safety devices. In the second stage of the experiments, an onboard safety device was installed on the test vehicle. The driving parameters and warning messages were recorded during the experiments. As shown in Table 6, the average speed of the vehicle was reduced around $10 \%$ and the maximum speed of the vehicle was decreased from $94.7 \mathrm{~km} / \mathrm{h}$ to $79.7 \mathrm{~km} / \mathrm{h}$ from the first to the second stage. The total travelling time in the second stage of experiment was three minutes longer than that in the first stage. From a safety point of view, the number of tailgating warning was reduced more than $50 \%$ and the braking number was greatly reduced from 88 times to 11 times from the first to the second stage. The reduction of braking number can be explained in two reasons. Firstly, the coasting distance was increased so that it spent less time on idling at the traffic lights. Secondly, the number of heavy decelerations were also decreased. These two results indicate the reduction of braking number on achieving fuel savings when the driver closely followed the instruction from the on-board safety device and drove in a more environmentally friendly and safe manner .

Table 6. Changes of driving parameters between both monitoring stages.

\begin{tabular}{|l|l|l|}
\hline & Stage 1 & Stage 2 \\
\hline Average speed $(\mathrm{km} / \mathrm{h})$ & 43.8 & 40.1 \\
\hline Maximum speed $(\mathrm{km} / \mathrm{h})$ & 94.7 & 79.7 \\
\hline Travelling time (minutes) & 46 & 49 \\
\hline Tailgating warning (times) & 108 & 50 \\
\hline Braking number (times) & 88 & 11 \\
\hline
\end{tabular}

The distributions of VSP modes were calculated to compare the percentage of time spent in different driving patterns, including deceleration, idling, acceleration and strong acceleration. Figure 5 shows the average time spent on different VSP modes without and with the on-board safety device. As shown in Figures $5 \mathrm{a}$ and $5 \mathrm{~b}$, the percentage of time spent in modes 1 and 2 is reduced by $4 \%$ from stage 1 to 2 . There is no significant difference in time spent in two stages of experiments for VSP mode 3. In the medium VSP modes 4 to 7 , the percentage of time spent is increased from $32.4 \%$ to $42.5 \%$ from stage 1 to 2 . The increase of average distribution from stage 1 to 2 in modes 4 to 7 can be related to a lower and steady speed of the vehicle as controlled by the on board safety device. It can be also explained as the driver controlled the speed of the vehicle more appropriately. In higher VSP modes 8 to 14, the percentage of time spent was decreased from $22.2 \%$ to $14.7 \%$ from stage 1 to 2 , due to the reduced time spent on excess speeding and strong acceleration in stage 2 during the experiments. With the installation of the on-board safety device, it is possible to observe the average time spent is shifting from higher to lower VSP modes. 


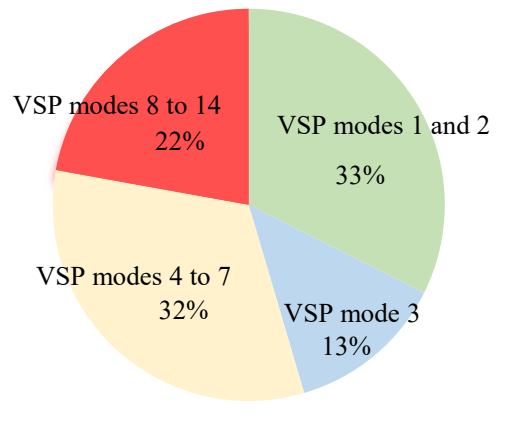

(a). Without on-board safety device (stage 1)



(b). With on-board safety device (stage 2)

Figure 5. Average time spent in each VSP mode

\section{Emissions and fuel consumption results}

Table 7 lists the results of vehicle emissions in two stages of experiments with and without the on-board safety device. After the installation of the on-board safety device, a reduction of $57 \%$ of $\mathrm{HC}$ and $25 \%$ of $\mathrm{CO}_{2}$ emissions was achieved, as the $\mathrm{HC}$ was reduced from $0.0013 \mathrm{~g} / \mathrm{s}$ without the on-board safety device to $0.0005 \mathrm{~g} / \mathrm{s}$ with the on-board safety device, and the $\mathrm{CO}_{2}$ from $18.2 \mathrm{~g} / \mathrm{s}$ to $13.7 \mathrm{~g} / \mathrm{s}$. This indicates a strong impact of the driving style on both $\mathrm{HC}$ and $\mathrm{CO}_{2}$ emissions. The reduction of $\mathrm{CO}_{2}$ was mainly due to the fuel consumption which was reduced from $0.006 \mathrm{~L} / \mathrm{s}$ without the device to $0.004 \mathrm{~L} / \mathrm{s}$ with the device. A reduction of $9 \%$ of $\mathrm{NO}_{\mathrm{x}}$ was found in the experiment results. Unexpectedly the $\mathrm{CO}$ emission was increased from $0.037 \mathrm{~g} / \mathrm{s}$ to $0.047 \mathrm{~g} / \mathrm{s}$. A previous study showed that different driving styles did not show distinct difference in CO emissions [18]. More experiments will be conducted to verify identify the underlying causes. The fuel consumption was estimated using a carbon balance methodology [19]. An average of $25 \%$ reduction of fuel consumption was achieved when the safety device was used.
Table 7. Impact of an on-board safety device on gaseous emissions and fuel consumption.

\begin{tabular}{|l|l|l|l|l|l|}
\hline & $\begin{array}{l}\mathrm{HC} \\
(\mathrm{g} / \mathrm{s})\end{array}$ & $\begin{array}{l}\mathrm{CO} \\
(\mathrm{g} / \mathrm{s})\end{array}$ & $\begin{array}{l}\mathrm{CO}_{2} \\
(\mathrm{~g} / \mathrm{s})\end{array}$ & $\begin{array}{l}\mathrm{NO}_{\mathrm{x}} \\
(\mathrm{g} / \mathrm{s})\end{array}$ & $\begin{array}{l}\text { Fuel } \\
\text { economy } \\
(\mathrm{L} / \mathrm{s})\end{array}$ \\
\hline $\begin{array}{l}\text { Normal driving } \\
\text { results }\end{array}$ & 0.0013 & 0.037 & 18.2 & 0.13 & 0.006 \\
\hline $\begin{array}{l}\text { Results with the } \\
\text { on-board safety } \\
\text { device }\end{array}$ & 0.0005 & 0.047 & 13.7 & 0.12 & 0.004 \\
\hline $\begin{array}{l}\text { Percentage of } \\
\text { change using the } \\
\text { device }\end{array}$ & $-57 \%$ & $26 \%$ & $-25 \%$ & $-9 \%$ & $-25 \%$ \\
\hline
\end{tabular}

To understand the results shown in Table 7, distributions of the emissions and fuel consumption in each of the VSP modes were calculated. Figure 6 shows the distribution of emissions over the VSP modes. After the installation of the on-board safety device, the emission rates in VSP modes 1 and 2 were reduced by $57 \%, 25 \%$ and $3 \%$ for $\mathrm{HC}, \mathrm{CO}_{2}$ and $\mathrm{NOx}$ respectively. However, the $\mathrm{CO}$ was increased by $20 \%$. It is reasonable to believe that $\mathrm{CO}$ emissions were not corresponding to the driving behavior when the test vehicle was decelerating. As shown in Figure 7, the fuel consumption of VSP modes 1 and 2 was reduced $25 \%$ when the on-board safety device was installed. This indicates a strong impact of the driving style such as reduction of braking number and an increase of the coasting distance on fuel economy as shown in the experimental results.

For VSP mode 3 , the emission rates of $\mathrm{HC}, \mathrm{CO}_{2}$ and $\mathrm{NOx}$ were reduced by $58 \%, 25 \%$ and $18 \%$ from stage 1 to stage 2 respectively. The significant reduction of $\mathrm{NO}_{\mathrm{x}}$ may be due to the lower temperature in the engine and/or the smaller air/fuel ratio when the vehicle was in idling condition. A reduction of $25 \%$ of fuel consumption was observed in VSP mode 3 when the on-board safety device was installed.

In the medium VSP modes 4 to 7 , the $\mathrm{HC}$ was reduced by $58 \%$ from $0.0003 \mathrm{~g} / \mathrm{s}$ without the on-board safety device to $0.0001 \mathrm{~g} / \mathrm{s}$ with the on-board safety device. The $\mathrm{CO}_{2}$ was reduced by $27 \%$ from $5.29 \mathrm{~g} / \mathrm{s}$ to $3.86 \mathrm{~g} / \mathrm{s}$ and the NOx by $10 \%$ from $0.04 \mathrm{~g} / \mathrm{s}$ to $0.03 \mathrm{~g} / \mathrm{s}$. This indicated a strong impact of the driving style on $\mathrm{HC}, \mathrm{CO}_{2}$ and $\mathrm{NOx}$ emissions were found when the test vehicle was accelerating. In addition, the average speed of the test vehicle was reduced around $10 \%$ after installation of the safety device. Therefore, a reduction of $27 \%$ of fuel consumption was achieved in modes 4 to 7 . This provided indication that the fuel economy can be influenced by the travelling speed of the vehicle.

In higher VSP modes 8 to 14 , the emission rates $\mathrm{HC}, \mathrm{CO}_{2}$ and $\mathrm{NOx}$ were reduced by $55 \%, 23 \%$ and $8 \%$ respectively from stage 1 to stage 2. The emission rate of CO was increased by $32 \%$ from $0.010 \mathrm{~g} / \mathrm{s}$ in stage 1 to $0.013 \mathrm{~g} / \mathrm{s}$ in stage 2 . This shows that $\mathrm{CO}$ emissions were weakly affected by the driving behavior. Furthermore, the driving behavior was not affected by a large portion of the variability of $\mathrm{CO}$ emission rates. After installation of the on-board safety device, the maximum speed of the vehicle was decreased from $94.7 \mathrm{~km} / \mathrm{hr}$ to $79.7 \mathrm{~km} / \mathrm{hr}$. With the lower and steady speeds of the test vehicle, the fuel consumption was reduced by $23 \%$ form the first stage to the second stage of experiments. 


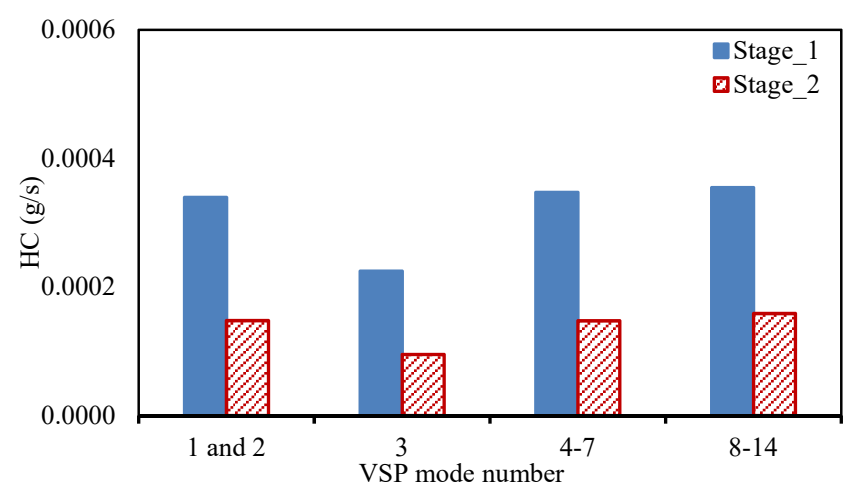

(a). $\mathrm{HC}$ emission

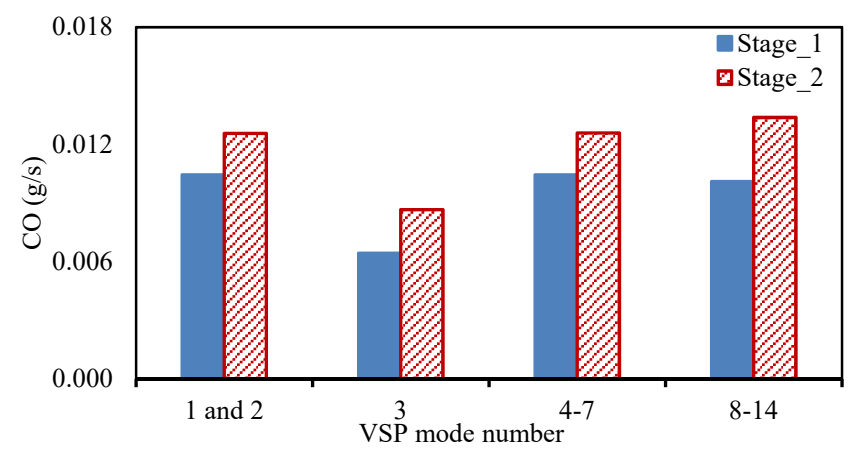

(b). $\mathrm{CO}$ emission

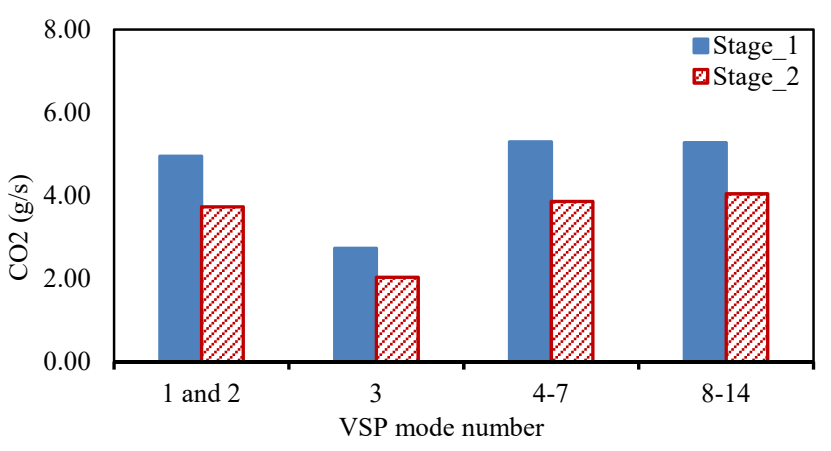

(c). $\mathrm{CO}_{2}$ emission

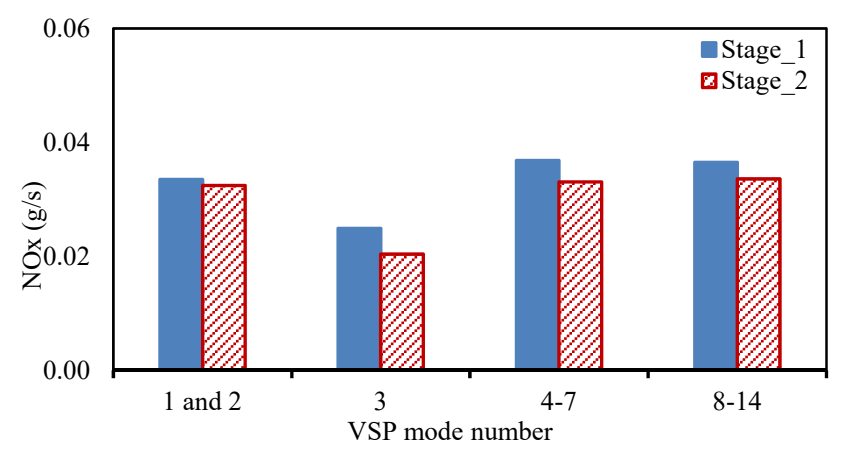

(d). $\mathrm{NO}_{\mathrm{x}}$ emission

Figure 6. The emissions in each group of the VSP modes in stages 1 and 2

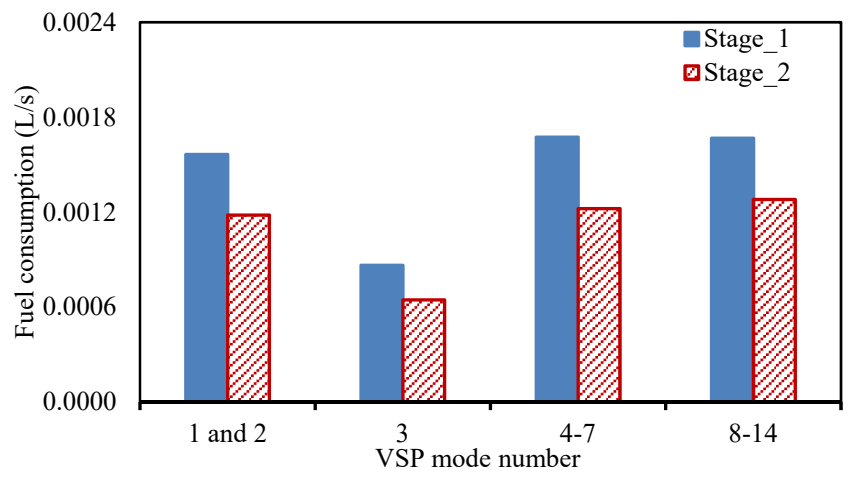

Figure 7. The fuel consumption in each group of the VSP modes in stages 1 and 2

\section{Conclusions}

In this study, the effect of an on-board safety device on the emissions and fuel consumption was investigated. It was assessed in terms of pollutant emissions, greenhouse emission and fuel consumption and their correlation with the driving behavior. A PEMS device was installed on a light goods vehicle. A specific driving route was designated for the experiments. The VSP methodology was applied to process and analyse the experimental data. The majors results can be summarised as follows.

1) The number of tailgating warning and braking was greatly reduced by $54 \%$ and $88 \%$ respectively when the on-board safety device was activated.

2) With the on-board safety device, the driver drove more carefully at a smoother speed than that without the safety device. In addition, the time spent on excessive speeding, strong acceleration and deceleration was reduced.

3) Strong impact of the on board safety device on fuel consumption and $\mathrm{HC}$ and $\mathrm{CO}_{2}$ emissions is identified based on the VSP analysis results. Compared with the results without the safety device, the average $\mathrm{HC}$ was reduced by $57 \%, \mathrm{CO}_{2}$ by $25 \%$, NOx by $9 \%$ and fuel consumption by $25 \%$ with the safety device. This was due to the driving behavior improved by reduced braking number, coasting distance and the number of tailgating events.

4) The distribution of emissions over the VSP modes was analyzed. Using the safety device, the reduction of $\mathrm{HC}$ was quite evenly distributed, $55 \%-58 \%$, over the VSP modes. The improved combustion with the safe device resulted in the decrease of $\mathrm{CO}_{2}$ and fuel consumtion. NOx was reduced by using the safety device more in the idling condition (VSP mode 3 ) than in other driving modes. CO was increased about $26 \%$ over all the driving modes.

5) By following the instruction from the safety device, the driver was driving not only more safely but also in a more environmentally friendly manner. Therefore on-board safety devices can be used not only for safety assurance but also for reducing the fuel consumption and vehicle emissions.

\section{References}

1. Nocera, S. and F. Cavallaro, Policy Effectiveness for containing CO2 Emissions in Transportation. Procedia Social and Behavioral Sciences, 2011. 20: p. 703-713. 
2. Lautso, K., et al., PROPOLIS - Planning and Research of Policies for Land Use and Transport for Increasing Urban Sustainability 2004

3. Atkinson, R.W., et al., The impact of the congestion charging scheme on ambient air pollution concentrations in London. Atmospheric Environment, 2009. 43: p. 54935500.

4. Ning, Z., M. Wubulihairen, and F. Yang, $P M$, NOx and butane emissions from on-road vehicle fleets in Hong Kong and their implications on emission control policy. Atmospheric Environment, 2012. 61(Supplement C): p. 265-274.

5. Alam, M.S. and A. McNabola, A critical review and assessment of Eco-Driving policy \& technology: Benefits \& limitations. Transport Policy, 2014. 35(Supplement C): $\mathrm{p}$. 42-49.

6. Sivak, M. and B. Schoettle, Eco-driving: Strategic, tactical, and operational decisions of the driver that influence vehicle fuel economy. Transport Policy, 2012.

22(Supplement C): p. 96-99.

7. Imaizumi, H. and K. Sengoku, Estimation of CO2 Reduction Potential in Japan by Traffic-Flow Smoothing and Eco-Driving Promotion. 2013, SAE International 2013-01-0621.

8. Beusen, B., et al., Using on-board logging devices to study the longer-term impact of an eco-driving course.

Transportation Research Part D: Transport and

Environment, 2009. 14(7): p. 514-520.

9. Orfila, O., G. Saint Pierre, and M. Messias, An android based ecodriving assistance system to improve safety and efficiency of internal combustion engine passenger cars. Transportation Research Part C: Emerging Technologies, 2015. 58(Part D): p. 772-782.

10. Dijksterhuis, C., et al., The impact of immediate or delayed feedback on driving behaviour in a simulated Pay-As-YouDrive system. Accident Analysis \& Prevention, 2015.

75(Supplement C): p. 93-104.

11. Transport Department. Table 4.4: Registration and Licensing of Vehicles by Fuel Type(April 2017). Viewed on 13 March 2018; Available from:

http://www.td.gov.hk/filemanager/en/content 4855/table44 .pdf.

12. Huang, Y., et al., Emission measurement of diesel vehicles in Hong Kong through onroad remote sensing:

Performance review and identification of highemitters.

Environmental Pollution, 2018. 237 p. 133-142.

13. Vaezipour, A., A. Rakotonirainy, and N. Haworth, Reviewing in-vehicle systems to improve fuel efficiency and road safety. Procedia Manufacturing, 2015. 3: p. 3192 3199.

14. Alzaman, C., Impact of optimisation on idle time's fuel consumption and $\mathrm{CO} 2$ emissions in urban transportation Int. J. Business Performance and Supply Chain Modelling, 2016. 8(2): p. 157-179.

15. Frey, H., N. Rouphail, and H. Zhai, Speed and FacilitySpecific Emission Estimates for On-Road Light-Duty Vehicles on the Basis of Real-World Speed Profiles. Vol 1987. 2006. 128-137.

16. José, J.-P.L., Understanding and quantifying motor vehicle emissions with vehicle specific power and TILDAS remote sensing. 1999, PH. D. Thesis Massachusetts Institute of Technology, Cambridge, MA.

17. Rolim, C.C., et al., Impacts of On-board Devices and Training on Light Duty Vehicle Driving Behavior. Procedia - Social and Behavioral Sciences, 2014. 111: p. 711-720.
18. Gallus, J., et al., Impact of driving style and road grade on gaseous exhaust emissions of passenger vehicles measured by a Portable Emission Measurement System (PEMS). Transportation Research Part D, 2017. 52: p. 215-226.

19. Burke, R.D., C.J. Brace, and J.G. Hawley, Critical evaluation of on-engine fuel consumption measurement. Proceedings of the Institution of Mechanical Engineers, Part D: Journal of Automobile Engineering, 2011. 225(6): p. $829-844$

\section{Contact Information}

Elvin C.Y. Ng

E-mail: elvin ng@vtc.edu.hk

\section{Acknowledgments}

This work is supported by Greensafety Technology Limited.

\section{Definitions/Abbreviations}

PEMS Portable emissions measurement system

CO Carbon monoxide

$\mathrm{CO}_{2} \quad$ Carbon dioxide

NOx Nitrogen oxides

VSP Vehicle specific power

$\mathbf{C H}_{4} \quad$ Methane

$\mathbf{N}_{2} \mathbf{O} \quad$ Nitrous oxide

DPF Diesel particulate filter

DOC Oxidation catalysts

OBD II On-board diagnostic II

GPS Global positioning system

EGR Exhaust gas recirculation

DOC Diesel oxidation catalyst

Page 7 of 8 
